\title{
Slogans in Higher Education: A Longitudinal Study (An Abstract)
}

\author{
Syed Tariq Anwar
}

\begin{abstract}
This study investigates and analyzes university/college slogans which play an important role regarding institution-specific positioning and digital marketing. By discussing the literature and morphological issues (word formation in sentences), the study investigates 1935 universities and 4-year colleges in the USA. Findings of this study reveal that nearly half of the institutions used slogans in 2007 on their Websites. At the same time, this number declined significantly after 7 years in 2014. These findings clearly support the notion that universities and colleges are showing limited interest regarding placing slogans on their Websites. Interest in slogans may be declining because of the appearance of new technology platforms and digital media. Findings of the study confirm that slogans help universities and colleges to seek identity and develop online marketing campaigns that aim at differentiating their academic programs and institutional image. The paper carries a meaningful value added in the areas of positioning and digital marketing which often change in higher education to deal with competition, digital technologies, and new delivery methods.
\end{abstract}

References available on request.

S.T. Anwar $(\bowtie)$

West Texas A\&M University, Canyon, TX, USA

e-mail: sanwar@mail.wtamu.edu 